The Buckingham Journal of Language and Linguistics 2015 Volume 8 pp 99-106

\title{
DIPHTHONGS IN KANASHI
}

\author{
Satarupa Dattamajumdar \\ sd@as.in
}

\begin{abstract}
Kanashi is identified as a Tibeto-Burman language of Sino-Tibetan language family. The language has been classified as a Kinauri language belonging to West-Himalayish group of Tibeto-Kanauri branch of TibetoBurman group. Kanashi has been referred by UNESCO as definitely endangered. Retrospective literature survey reveals that the language is yet to be documented properly. Therefore as a part of language documentation the phonological studies of Kanashi have been undertaken. The study of diphthongs of the language has been considered in the present paper. Diphthongs are the phonological segments where two vowels form clusters to form a single syllable. The data of the present paper has been collected from Kanashi native speakers during field investigation in Malana village of Himachal Pradesh. IPA has been used for data collection.
\end{abstract}

\section{INTRODUCTION}

The language spoken in the Malana village of Kullu district of Himachal Pradesh is widely known by the name Kanashi. Malani is the alternative name of the language. The native speakers prefer to call their language Malani. According to http://archive.ethnologue.com ${ }^{1}$ the speaker strength of Kanashi is 1,400 . The number of speakers is 1500 according to UNESCO report.

According to the scholars, like Sharma (1989: 2$)^{2}$ genealogically, Kanashi is identified as a Tibeto-Burman language of Sino-Tibetan language family. The language has been classified as a Kinauri language belonging to WestHimalayish group of Tibeto-Kanauri branch of Tibeto-Burman group. It is said to be related with Milchang, a sub- branch of Kinnauri group of languages. That Kanashi language is an admixture of Sanskrit and Tibetan

1 http://archive.ethnologue.com/xns. 17 $7^{\text {th }}$ edn.,2013 (Retrieved. on 10.04.2014:18 hours)

${ }^{2}$ Sharma,D.D. (1989).Tribal Languages of Himachal Pradesh. Pt.:1.Delhi: Motilal Publications. 
varieties has been stated by Bangroo and Stronski(2002) ${ }^{3}$. The language is lesser known and has no written form. The language has been reported to have no intelligibility with the neighboring languages spoken in Lahul-Spiti and Kinnaur (source: Kanashi Informant). Kanashi has been referred by UNESCO as definitely endangered. Retrospective literature survey reveals that the language is yet to be documented properly. Therefore as a part of language documentation the phonological studies of Kanashi have been undertaken. The study of diphthongs of the language has been considered in this present paper.

The data of the present paper has been collected from Kanashi native speakers during field investigation in Malana village of Himachal Pradesh. IPA has been used for data collection.

\section{DIPHTHONG}

Diphthongs are the phonological segments where two vowels form clusters to form a single syllable. In such vowel clusters the first element holds the syllabic peak and the second (or last) component being non-syllabic in nature lacks in syllabic prominence. In a diphthong the first component, which is called vowel nucleus is prominent and the second element being nonsyllabic is less prominent and is called 'glide'.

The data of the present study attests twenty six diphthongs in the Kanashi language. Depending upon the position, height and the direction of movement of the tongue for production of two vowel components in conjunction, Kanashi diphthongs have been classified into four types. These are listed and categorized with examples in the following.

\section{Diphthongs with Identical Components}

As discussed in Dattamajumdar (2002:70) "The diphthongs of this type are those, where both the vowels involved in the structure are identical or same. The difference among them is only regarding stress. The first component carries the syllabic stress whereas the final (or the second component i.e., the same vowel) is unstressed." Kanashi attests five identical diphthongs which are presented below.

1. /ï̌l e.g., /riŭd/ 'third day back'

2. /oŏ/ e.g., /poŏm/ 'snow'

3. /uŭ/ e.g., /duŭr/ 'distance'

3 Bangroo,V. and Stronski,K. (2002). 'Malana:Shangrila in the Himalayas' IGNCA. www.Kanashi Language Wikipedia. (Retrieved on $25^{\text {th }}$ January 2013) 
VOLUME 8

4. /eĕ/ e.g., /heĕd/ 'another'

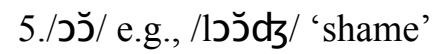

\section{HORIZONTAL DIPHTHONGS}

Horizontal diphthongs are "The diphthongs in which both the vowels belong to the same height... The difference between the two components is, one of them is front and the other, a back vowel" (Dattamajumdar 2002: 71). Depending upon tongue movement that is, from the initial component to the final component, horizontal diphthongs in Kanashi can be of two sub types--movement from front to back and from back to front. Examples are given below.

1. /ǔ̌l e.g., /guǐ/ 'me(also)'

2. /iŭ/ e.g., /dziŭ/ 'animal'

3. /eŏ/ e.g./beŏra/ 'dull'

4. /oě/ e.g., /khoě/ 'why'

The directions of the above mentioned diphthongs are represented by 'vector' lines in the following vowel chart.

Figure No. 1

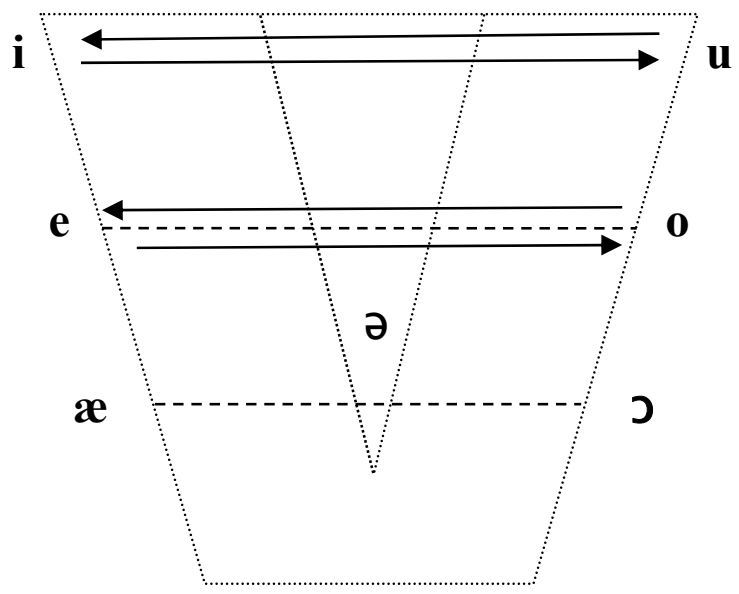

$\mathbf{a}$

\section{VERTICAL DIPHTHONGS}

Vertical diphthongs are produced when the tongue moves from a lower vowel to a higher vowel or higher vowel to lower vowel. The tongue position 
may involve change by one degree, two degree of three degree of vowel height. This may involve both 'closing' and 'opening' of the oral cavity.

The diphthongs which involve 'closing' and 'opening' by one degree raising or lowering of the tongue height are presented in the following

1. /iě/ e.g., /didßziniĕta/ ' than(comparison)'

2. /ě̃/ e.g., /d herye/ 'like that'

3. /วŏ/ e.g., / Jวŏ/ 'husband'

The directions of the above diphthongs are represented by 'vector' lines in the following vowel chart.

\section{Figure No.2}

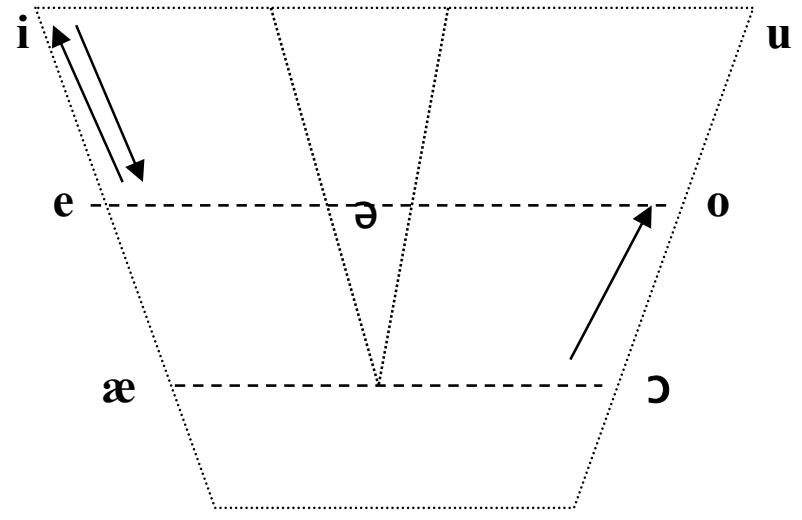

$\mathbf{a}$

The diphthongs which involve 'closing' and 'opening' by two degree raising or lowering of the tongue height are presented in the following

1. /oŭ/ e.g., /soŭdə/ 'sweet meat'

2. /u丂̆/ e.g., / uŏy/ 'udder'

3. /aě/ e.g., /aě/ 'affirmation'/

4. aŏ/ e.g., /1 aŏ/ 'sing'

The directions of the above diphthongs are represented by 'vector' lines in the vowel chart below.

The diphthongs which involve 'closing' and 'opening' by three degree raising or lowering of the tongue height are presented in the following

1. /iă/ e.g., /biăn/ 'corriander'

2. /aǐ/ e.g.,/naĭy/ 'river' 
THE BUCKINGHAM JOURNAL OF LANGUAGE AND LINGUISTICS

VOLUME 8
3. /aŭ/ e.g., /daŭ/ 'elder sister'
4. /uă/ e.g., / uăn/ 'hunger'

The directions of the above diphthongs are represented by 'vector' lines in the following vowel chart.

Figure-3

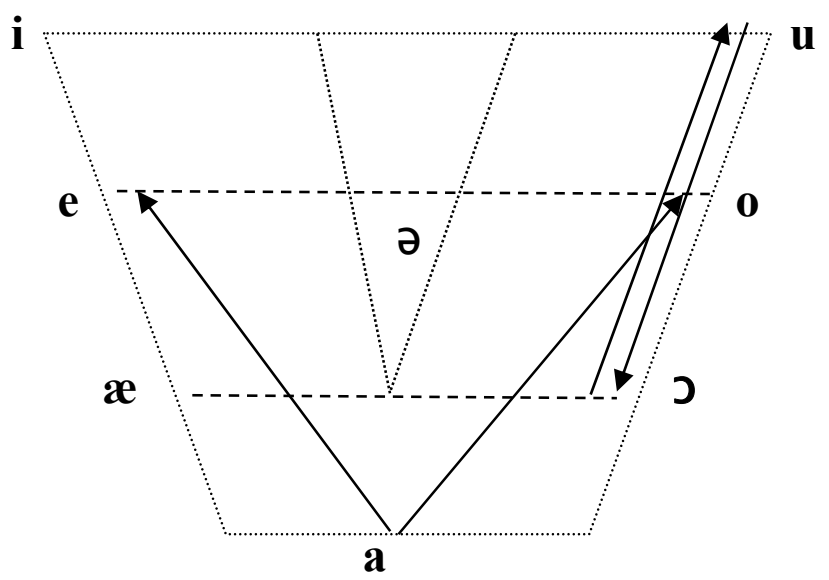

Figure-4

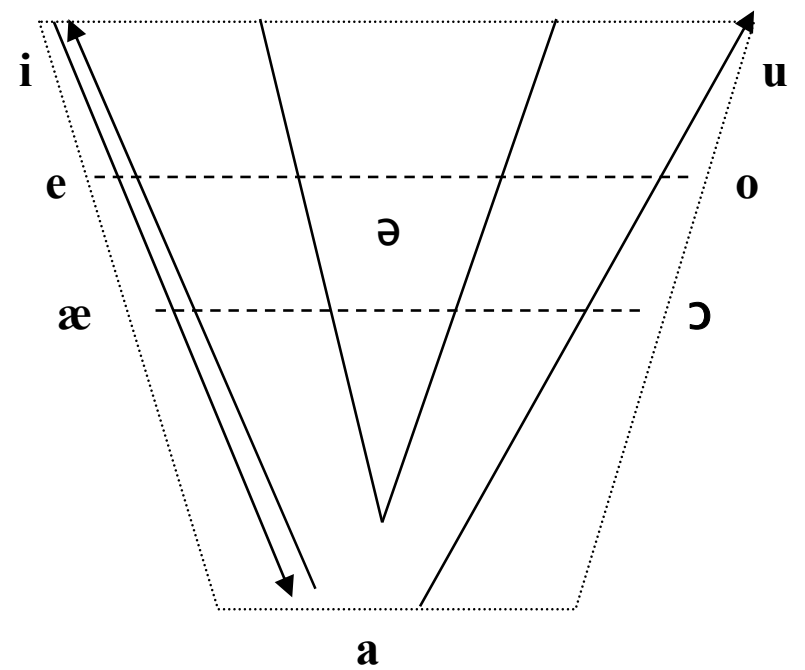




\section{DIAGONAL DIPHTHONGS}

The diphthongs which involve 'closing' (i.e., by raising the height of the tongue position) or 'opening' (i.e., by lowering the height of the tongue position) along with simultaneous 'backing' or 'fronting' are called diagonal diphthongs. The tongue position may involve change by one degree or two degree of vowel height.

A. The diphthongs which involve 'closing' and 'opening' by one degree raising or lowering of the tongue height are presented in the following.

$$
\begin{aligned}
& \text { /eŭ/ e.g. /sotfeŭ/ 'think' } \\
& \text { uě/ e.g., /uĕ[כ઼/ 'evening', } \\
& \text { /دĕ/ e.g., /kכĕsכy/ 'copper' }
\end{aligned}
$$

The directions of the above diphthongs are represented by 'vector' lines in the following vowel chart.

Figure no. 5

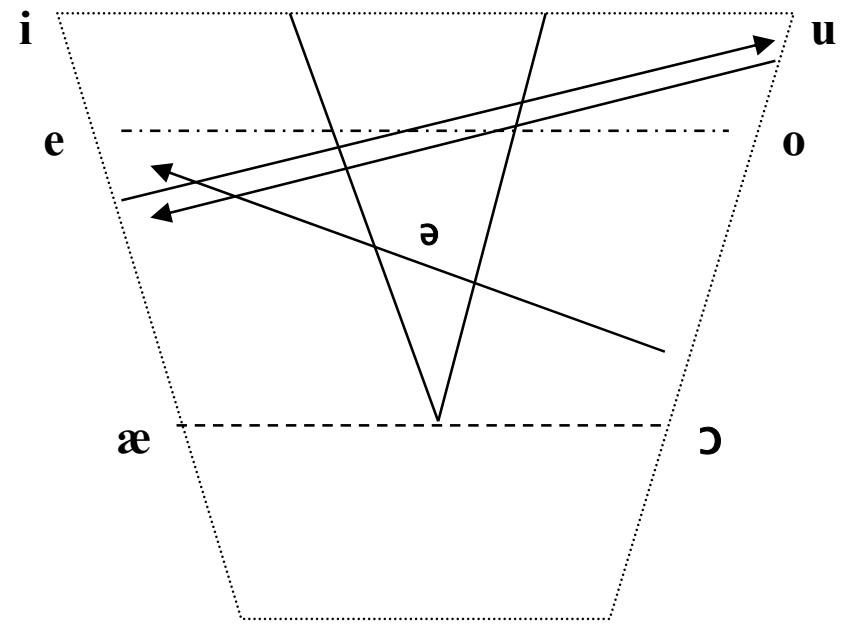

$\boldsymbol{a}$

B. The diphthongs which involve 'closing' and 'opening' by two degree raising or lowering of the tongue height are presented in the following

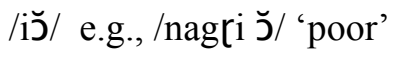

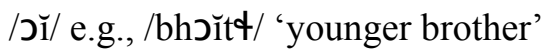

/oă/ e.g., /goărكu/ 'scratch' 


\section{VOLUME 8}

The directions of the above diphthongs are represented by 'vector' lines in the following vowel chart.

\section{Figure no.6}

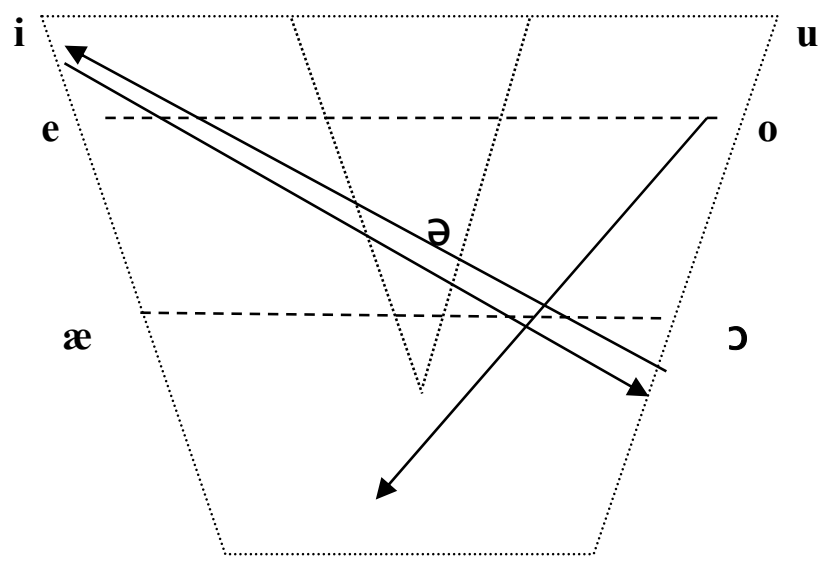

a

Acknowledgement: I am extremely thankful to Prof. Ashoke Kumar Datta and Shri Amlan Datta of Bom-Bom Charitable Trust for initiating me in the present study and helping me to collect the data. I am grateful to my teacher Prof. Krishna Bhattacharya for her valuable suggestion which has helped me in identifying the speech sounds of the Kanashi language.

\section{REFERENCES}

Abercrombie, D. 1967. Elements of General Phonetics. Edinburgh: Edinburgh University Press.

Bangroo,V. and K. Stronski. 2002. 'Malana: Shangrila in the Himalayas' IGNCA. www.Kanashi Language Wikipedia. (Retrieved on $25^{\text {th }}$ January 2013)

Bhattacharya,K. 1988. Bengali Phonetic Reader. Mysore:CIIL.

Catford, J.C. 1977. Fundamental Problems in Phonetics. Edinburgh: Edinburgh University Press.

Chatterjee, S. 1972. 'The Diphthongs of Standard Colloquial Bengali'. Calcutta Orientals, 1:1, 27-33. Calcutta.

Dattamajumdar, S. and M. Indu 2002. 'Developmental Status of Bangla diphthongs in the Language Acquisition of the Hearing Impaired Children' In: IJL, vol.21,5867.

Dattamajumdar,S. 'Reduplication in Kanashi' In: Buckingham Journal of Language and Linguistics. 2013. vol.6, 95-104. 


\section{DIPHTHONGS IN KANASHI}

Dattamajumdar, S. 2013. 'Towards a Written Form of The Kanashi Language (An Endangered Language of Himachal Pradesh)' In: V.I.S. Commemoration Volume. ISDL (forthcoming)

http://archive.ethnologue.com/xns. 17 $7^{\text {th }}$ edn., 2013 (Retrieved. on 10.04.2014:18 hours)

Ladefoged, P. 1993. A Course in Phonetics. ( $3^{\text {rd }}$ edn) first edn. 1975. New York: Harcourt Brace, Iovanorich.

Laver, J. 1994. Principles of Phonetics. Cambridge: The University Press.

Sharma, D.D. 1989.Tribal Languages of Himachal Pradesh. Pt.:1 \&II. Delhi: Motilal Publications. 